\title{
EXPERIENCIA
}

A AUTORA

Jussara de Lara Sanches Martins

Professora do ensino fundamental da Escola Estadual Dr. Cardoso de Almeida - Botucatu/ SP

\section{LEITURA E COMPREENSÃO DA BULA DE REMÉDIO}

Alunos de terceira série do ensino fundamental lêem a bula de remédio, procurando entender os significados dos termos técnicos

$\mathrm{F}$

oi a falta de interesse com relação à leitura extra-escolar por aproximadamente $90 \%$ dos alunos de terceiras séries, com a qual trabalho, no período da tarde, deste educandário público estadual, que me levou a pensar na importância de um projeto que tivesse a leitura como base.

Mesmo a escola fornecendo livros, percebi que os alunos, apesar de manifestarem-se interessados em obter o empréstimo deles, muitos demonstravam ter dificuldades, à medida que não tinham condições de relatar à professora e aos colegas o conteúdo do texto, chegando a efetuar a devolução da obra, sem ter realizado a leitura.

A preocupação de desenvolver o hábito de leitura, vinculado às necessidades práticas do dia-a-dia, levaram-me a propor a leitura e análise das bulas de medicamentos. As bulas são de acesso fácil a todas as crianças, sem a necessidade de aquisição de uma obra específica para ser utilizada com esse objetivo. Além disso, é indiscutível a importância de despertar no aluno o interesse pela leitura objetiva, com informações úteis e educativas para a criança e sua família, vinculando a leitura às práticas do cotidiano e desenvolvendo, inclusive, novos hábitos com relação ao consumo de remédios.

\section{OBJETIVOS E METODOLOGIA}

Organizamos o trabalho com o projeto de leitura de bulas de remédio em etapas. Solicitamos a cada aluno da terceira série que trouxesse à sala de aula, para ser utilizada durante as aulas de Português, uma bula de qualquer remédio usado atualmente em sua casa, por seus familiares. Em seguida, desenvolvemos com os alunos um processo de diálogo. Conversamos, em sala de aula, sobre o motivo de a família de cada aluno adquirir tal medicamento e como estava, naquele momento, a saúde do familiar que consumia ou consumiu o remédio. A esta etapa seguiu-se a leitura 
silenciosa, pelo aluno, da bula objeto do trabalho.

Depois da primeira leitura silenciosa, abrimos a discussão para que os alunos fizessem os comentários sobre a leitura efetuada e as dificuldades encontradas durante a realização dessa etapa. $\mathrm{O}$ objetivo principal foi o de identificar as dificuldades com os termos técnicos extremamente alheios ao nosso vocabulário cotidiano e que interferem na compreensão para o uso adequado do medicamento. Tal dificuldade acaba gerando, no usuário de medicamentos, um comportamento que o leva a ignorar a existência da bula e como sua leitura pode ajudar a esclarecer muitas dúvidas.

Com a preocupação de chamar a atenção do aluno para aquelas palavras de difícil compreensão e novas em seu vocabulário, passamos para a leitura oral, por alguns alunos, das bulas menores, para evitar o cansaço e desinteresse dos demais, bem como pelas dificuldades encontradas durante a leitura individual quanto aos termos técnicos e/ou científicos presentes.

Finda a leitura oral, ficou claro para os alunos que alguns termos técnicos repetemse em todas as bulas e que é necessário conhecê-los melhor para bem utilizar o remédio. Passamos, então, a destacar alguns itens comuns a todas as bulas, tais como: composição, posologia, indicações, contraindicações, fórmula, uso, informações técnicas ao paciente, entre outras. A pesquisa em dicionários sobre os significados da palavra bula e dos demais termos técnicos encontrados em comum foi realizada pelo aluno. Este processo foi bem interessante, pois pudemos perceber o interesse pelo assunto, a curiosidade para encontrar o significado mais adequado ao objeto de estu- do e a grande participação e solidariedade entre os alunos. Aqueles que tinham mais facilidade de manuseio do dicionário e compreensão da tarefa dispunham-se a ajudar o companheiro em dificuldades.
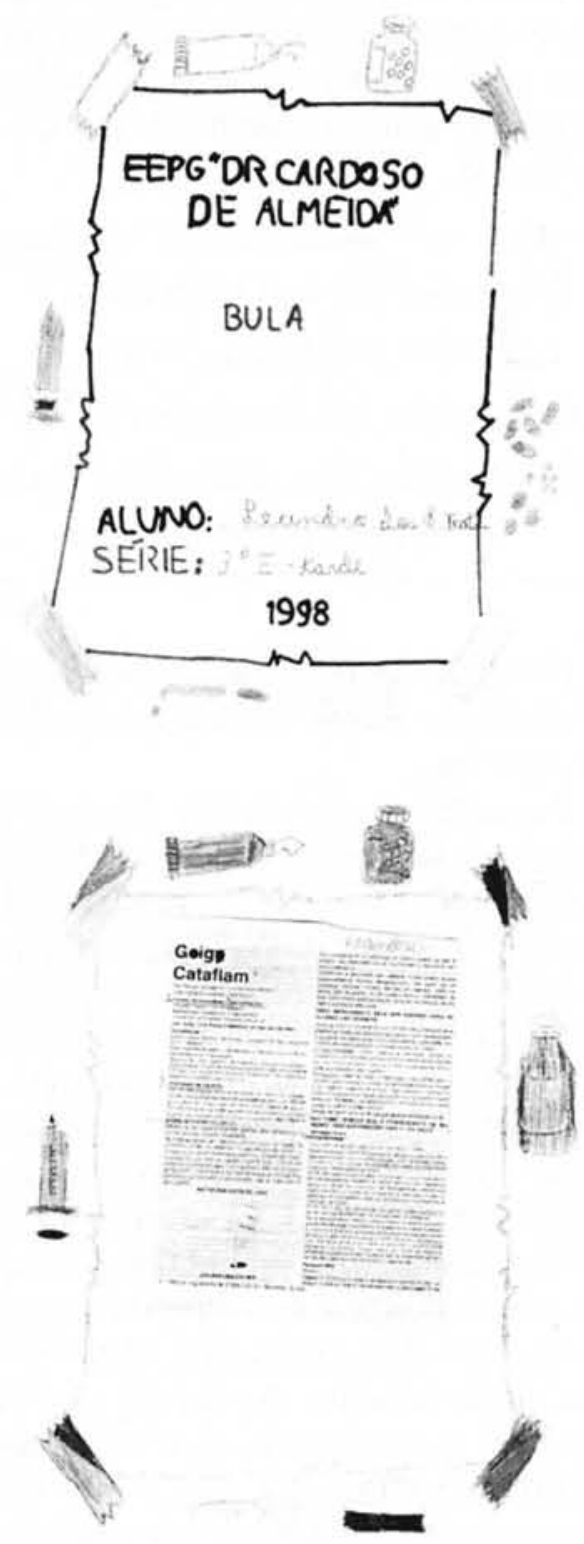

O aluno Leandro dos S. Bartoli analisou a bula do remédio Cataflan. 
Após chegarmos a um acordo sobre os significados mais adequados, passamos para o registro dos resultados. Este registro foi feito em formulário próprio, distribuído pela professora. Com a discussão e troca de idéias para a melhor, mais objetiva e esclarecedora elucidação de cada item a ser registrado, passamos a uma enumeração e à escrita do significado dos itens em estudo.

\section{Dissecamos as bulas em 15 partes comuns, com o respectivo esclarecimento da informação que cada uma traz a nós, leitores.}

Essa etapa foi a mais demorada, para a qual utilizamos quatro aulas, distribuídas em dois dias.

Posteriormente ao registro dos significados dos termos destacados, os alunos passaram para a etapa de preparação do relatório de pesquisa. Preparação da capa do trabalho, a da folha destinada à fixação, com cola, da bula pesquisada pelo aluno. Foi usada mais uma aula para essa etapa.

O trabalho foi montado, com a ordenação das páginas, com os registros dos significados, a capa e a bula, acrescidas de duas outras contendo várias perguntas, com o objetivo de averiguar o que o aluno aprendeu no decorrer da realização deste trabalho. As folhas com as questões avaliativas foram levadas, anteriormente, para casa, com a intenção de que fossem respondidas com a participação dos pais ou responsável, para que estes tomem ciência do trabalho realizado e, de maneira sutil, demonstrem a valorização da leitura e do trabalho desenvolvido pelo aluno. E ainda, proporcionar ao aluno a percepção de quanto é agradável sentir que há interesse deste(s) familiar(es) em atuar em conjunto na realização da tarefa escolar.

\section{AVALIAÇÃO DO DESEMPENHO DOS ALUNOS}

Fiquei extremamente satisfeita com o interesse dos alunos no decorrer do desenvolvimento das etapas deste trabalho. Posso até revelar, em certos momentos, fiquei emocionada com a expressão de solidariedade, companheirismo, cooperativismo entre os alunos. As atitudes tais como: trazer bulas extras para os colegas que não dispunham deste material na primeira aula, auxílio para localizar, na bula, o item abordado no momento da discussão, procura conjunta no dicionário dos termos estranhos, atenção extrema na formulação dos textos explicativos, indagações sobre o fato de se na aula seguinte continuaríamos os registros foram constantes durante todo o período do projeto. Outra constatação foi a de redução das faltas e, quando estas ocorriam, percebia-se a ânsia em colocar os próprios registros em dia, zelo para com a qualidade ortográfica dos textos explicativos, formulados coletivamente, dentre outras ocorrências. Mas o clímax de satisfação se deu quando fui indagada sobre a possibilidade de o aluno levar o trabalho concluído para sua casa, para que seus pais pudessem lê-lo.

Os resultados foram excelentes, atenderam além de minhas expectativas tanto na conduta dos alunos no decorrer da 
realização da etapas do trabalho, como foi relatado acima, quanto durante a elaboração das discussões e da execução dos registros dos textos. Esse comportamento promoveu como resultado a elaboração de textos claros, objetivos e simples. $\mathrm{O}$ fato que mais me surpreendeu foi a participação dos pais ao ajudarem os filhos na parte que solicitava essa atuação. Sendo assim, as informações extrapolaram o limite da sala de aula, abrangendo o lar de cada aluno, informando, quem sabe, o próprio usuário do medicamento, cuja bula foi nosso objeto de estudo.
Resumo: Professora da terceira série do ensino fundamental da escola estadual $\mathrm{Dr}$. Cardoso de Almeida, Botucatu, São Paulo, desenvolve projeto de leitura de bula de medicamentos com seus alunos. $\mathrm{O}$ objetivo é o de permitir ao aluno perceber a importância do hábito de leitura para seu cotidiano, como ela é útil e traz informações fundamentais. As atividades foram desenvolvidas levando-se em conta as dificuldades dos alunos em compreender os termos técnicos/científicos, fazendo-os pesquisar os sentidos no dicionário e registrálos através da escrita em trabalhos que foram montados e encaminhados para avaliação conjunta com ajuda dos pais. A professora pôde constatar a dedicação e interesse dos alunos, bem como a colaboração dos pais no desenvolvimento do trabalho.

Palavras-chave: Português, leitura, bula de remédios, dicionário, alunos de terceira série
(Reading and understanding medicine insert leaflets)

Abstract. A third grade teacher of the Dr. Cardoso de Almeida State School, in Botucatu, São Paulo, is developing a medicine insert leaflet reading project with her students. The purpose is to allow the student to perceive the importance reading has in day-to-day life and to show how important and how useful it is in bringing people basic information. The activities were carried out considering the difficulties students have to understand technical/scientific terms, making them research meanings in the dictionary and register them in papers elaborated and sent for joint evaluation by the student's parents. The teacher noticed how dedicated and interested the students were and how their parents collaborated with the project.

Key words: Portuguese, reading, medicine insert leaflets, dictionary, third grade students 